\title{
Regional estimation of parameters of a rainfall-runoff model at ungauged watersheds using the "spatial" structures of the parameters within a canonical physiographic-climatic space
}

\author{
Yeshewatesfa Hundecha, ${ }^{1}$ Taha B. M. J. Ouarda, ${ }^{1}$ and András Bárdossy ${ }^{2}$ \\ Received 16 August 2006; revised 7 June 2007; accepted 27 August 2007; published 22 January 2008.
}

[1] A regionalization scheme by which parameters of a continuous rainfall-runoff model are estimated from physiographic and climatic watershed descriptors is presented. The approach makes use of the spatial structures displayed by the parameters within a physiographic-climatic space defined on the basis of a canonical correlation analysis between model parameters and watershed descriptors. Traditionally, regionalization has been performed using a two-step procedure of first estimating the model parameters in a set of subwatersheds independently and then establishing a relationship between the parameters thus estimated and a set of watershed descriptors. The approach presented in this paper follows a procedure by which the two steps are combined into one. The model is calibrated for the training subwatersheds with a dual objective of maximizing the model performance and achieving well-defined spatial structures of the parameters within the physiographic-climatic space. The model parameters in the subwatersheds that are not used for training are estimated from the optimum parameters obtained in the training set of subwatersheds using ordinary kriging within the physiographic-climatic space. The performance of the model in these subwatersheds is comparable to the performance in the training set obtained using the optimum parameters estimated through model calibration. The results also indicate the possibility of extrapolation of the model parameters under a situation where some of the watershed descriptors lie slightly outside the range within which the training was done.

Citation: Hundecha, Y., T. B. M. J. Ouarda, and A. Bárdossy (2008), Regional estimation of parameters of a rainfall-runoff model at ungauged watersheds using the "spatial" structures of the parameters within a canonical physiographic-climatic space, Water Resour. Res., 44, W01427, doi:10.1029/2006WR005439.

\section{Introduction}

[2] Rainfall-runoff models have been widely used as tools for the prediction of streamflow resulting from meteorological driving forces. They have enjoyed a wide range of practical applications such as estimation of design flows in engineering practice, assessment of the impact of environmental changes in a watershed, and climate change impact studies. The traditional paradigm of their application generally follows a two-stage procedure: parameterization of the model using a set of observed historical meteorological and runoff data through model calibration; and implementation of the calibrated model for prediction.

[3] Estimation of model parameters, however, is often a difficult task; especially in ungauged watersheds, for which there is no historical observed runoff data to calibrate the model with. Application of a distributed physically based

\footnotetext{
${ }^{1}$ Eau, Terre et Environnement, Institut National de la Recherche Scientifique, University of Quebec, Quebec, Quebec, Canada.

${ }^{2}$ Institute of Hydraulic Engineering, Universität Stuttgart, Stuttgart, Germany.
}

Copyright 2008 by the American Geophysical Union. 0043-1397/08/2006WR005439\$09.00 model, whose parameters can be estimated a priori from physical watershed properties, might be a solution. However, because of the difficulty of upscaling the measured parameters at small scale to a scale consistent with the spatial descritization within the model, it is practically difficult to fix the model parameters a priori without calibrating the model against observed watershed response. Even with the availability of watershed response data, it is not always easy to apply distributed physically based models because of their demand for a detailed data set, which may not be available for many watersheds. Therefore there is still a need to work with more parsimonious lumped models whose parameters are not directly related to the watershed properties.

[4] A handful of research efforts have been carried out in the recent past to regionalize parameters of conceptual models on the basis of different sets of physiographic and climatic attributes of a watershed [Abdulla and Lettenmaier, 1997; Post and Jakeman, 1999; Seibert, 1999; Fernandez et al., 2000; Hundecha and Bárdossy, 2004; Merz and Blöschl, 2004; Heuvelmans et al., 2006; Young, 2006]. Such an approach can potentially be exploited to handle the ungauged watershed problem and as a modeling scheme to assess the impact of changes in watershed attributes, such 
as land use. Indeed, their potential usage depends on the watershed attributes that are used to regionalize the parameters. Unless the land use attributes of the watershed are used to regionalize the model parameters, the approach would be of little importance in assessing the effect of land use changes. Similarly, if the parameters are regionalized on the basis of certain indices derived from streamflow, applicability of the approach in ungauged watersheds is not apparent.

[5] A common feature shared by most of the regionalization approaches reported so far is that they follow the two-stage procedure of first calibrating the model for individual subwatersheds without any reference to the watershed attributes and then fitting an assumed mathematical relationship between the set of watershed attributes and the model parameters. A linear regression is often used to establish the relationship. However, because of the problem of equifinality, a unique set of parameters is not generally achieved through model calibration [Duan et al., 1992; Beven and Freer, 2001]. There are many equally competing parameter sets that lead to a similar model performance and model calibration yields just one set among them. It is therefore difficult to get a well-defined relationship between the model parameters and the watershed descriptors. Fernandez et al. [2000] and Hundecha and Bárdossy [2004] devised a methodology in which they performed the model calibration and the fitting of the relationship between the model parameters and the watershed descriptors simultaneously thereby identifying parameters that display a defined relationship with the watershed descriptors.

[6] The work presented in this paper is a methodological advancement of the work by Hundecha and Bárdossy [2004], which was done on regionalization of parameters of the HBV model [Bergström, 1995; Lindström et al., 1997] for subwatersheds of the Rhine basin. A linear relationship between the model parameters and a set of watershed attributes was assumed by Hundecha and Bárdossy [2004]. However, a linear relationship doesn't necessarily reflect the inherent relationship that might exist between model parameters and the corresponding set of watershed attributes.

[7] The intention in this work is to investigate an approach for the estimation of model parameters from watershed attributes on the basis of a measure of similarity of watersheds within a space defined using a set of physiographic and climate descriptors. The measure of similarity of watersheds can be defined using an appropriate distance metric within this physiographic-climatic space. The defined distance metric serves as a better measure of similarity of watersheds in terms of their hydrological response than a distance defined on the basis of their geographic locations. It can therefore be used as a basis for regionalization of watershed responses or model parameters. McIntyre et al. [2005] implemented this approach for the regionalization of watershed runoff for prediction in ungauged watersheds. In the present study, we implement a physiographic-climatic space defined using coordinates derived from canonical correlation analysis of model parameters and watershed descriptors. We further make use of the "spatial" structure of each of the model parameters, which is modeled using a variogram function in the physiographic-climatic space to estimate parameters at ungauged watersheds. A similar approach was implemented for the regional estimation of flood frequency by Chokmani and Ouarda [2004].

[8] In the present work, the approach is implemented for the regional estimation of parameters of the HBV model with a different procedure. The estimation is carried out by simultaneously calibrating the model for 30 subwatersheds with a dual objective of maximizing the overall model performance and obtaining a well-defined spatial structure for each of the parameters within the physiographic-climatic space. Model parameters for the other subwatersheds are subsequently estimated through kriging from the parameter values of the calibration set of subwatersheds using the variograms describing the spatial structure of the parameters obtained during the calibration phase.

\section{Study Area and Data Set}

[9] The study was carried out on part of the Rhine basin located downstream of the gauge Maxau, located in the upper Rhine and upstream of Lobit, located in the lower Rhine. It has a total area of $109,330 \mathrm{~km}^{2}$. The watershed is subdivided into 101 subwatersheds of area ranging between $400 \mathrm{~km}^{2}$ to $2100 \mathrm{~km}^{2}$ (Figure 1). Part of the upper Mosel is located in France and since meteorological data for this part were not available for this work, six of the subwatersheds in the upper Mosel were left out of the study and the remaining 95 subwatersheds were considered for further study.

[10] The study area is characterized by different topographic structures ranging from hilly areas in the south and eastern part with elevation up to $1000 \mathrm{~m}$ a.s.1. to predominantly flat features in the lower part of the basin with elevation as low as $10 \mathrm{~m}$ a.s.1. The land cover within the basin also ranges from predominantly forest cover in the Sieg subbasin to a predominantly urban structure in the lower Rhine area.

[11] Digital maps of elevation, soil type, and land use were obtained at a resolution of $1 \mathrm{~km} \times 1 \mathrm{~km}$ from The International Commission for the Hydrology of the Rhine basin, CHR. Meteorological data were also obtained from the German Weather Service (DWD) for the period 1960-1998. These include daily precipitation amounts at 950 stations, daily maximum and minimum temperature at 250 stations, as well as relative humidity measured at $2 \mathrm{PM}$ at the temperature stations.

[12] Daily precipitation and daily mean temperature were interpolated on a $5 \mathrm{~km} \times 5 \mathrm{~km}$ grid over the study area using external drift kriging [Ahmed and deMarsily, 1987] by implementing a function of the topographic elevation as a drift variable [Hundecha and Bárdossy, 2004]. The longterm mean monthly evapotranspiration for different types of crops and forests were estimated using the Haude [1955] approach. The method is based on Dalton's law of evaporation, which considers evaporation as a process controlled by the vapor pressure difference between the evaporating surface and the atmosphere. The approach requires daily series of mean air temperature and relative humidity as well as crop coefficients for different types of vegetation.

\section{Methodology}

\subsection{Rainfall-Runoff Model}

[13] A semidistributed conceptual model of the Swedish Meteorological and Hydrological Institute (SMHI), the 


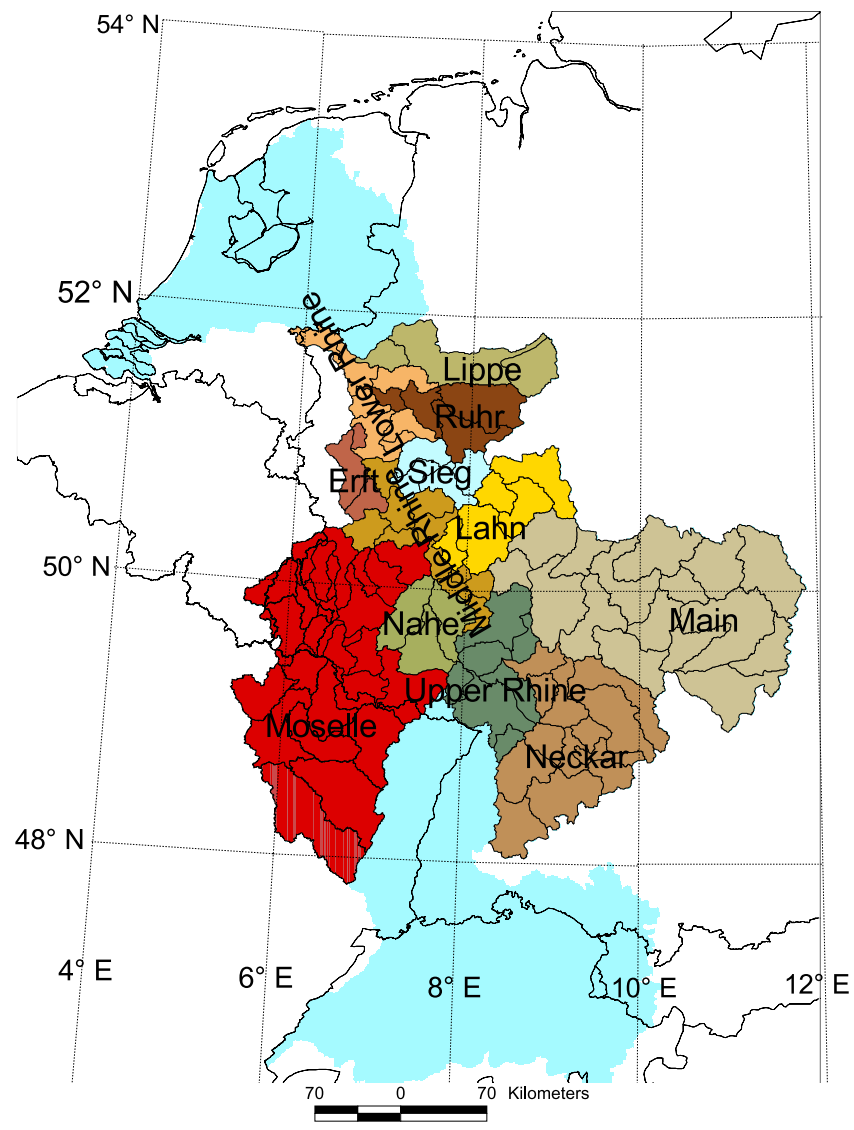

Figure 1. Part of the Rhine watershed subdivided into mesoscale subwatersheds.

HBV model [Bergström, 1995; Lindström et al., 1997] was used in the study. The model has components for the computation of snow accumulation and melt, soil moisture accounting, and runoff response. The snow accumulation and melt routine uses the degree day method. The soil moisture accounting routine computes the proportion of rainfall or snowmelt that is converted into runoff as a ratio of soil moisture and field capacity of the soil $F C$ raised to a parameter $\beta$. The remaining portion is added to the soil moisture. Soil moisture is depleted by evapotranspiration, which is controlled by the actual soil moisture and the potential evapotranspiration. A threshold moisture content $L P$ is defined above which evapotranspiration reaches its potential value. Below this value, the actual evapotranspiration reduces linearly to zero for a completely dry soil.

[14] The routines for snow accumulation and melt as well as soil moisture accounting are both applied in a distributed manner on homogeneous zones defined on the basis of elevation, soil type, and land use class. The elevation zones are defined using a $100 \mathrm{~m}$ contour interval, with areas between successive intervals considered homogeneous in terms of elevation. Each elevation zone is further subdivided into six soil zones, which are predominant in the study area (Lithosol, Ranker, Rendzina, Cambisol, Fluvisol, and Podzol). Four land use classes are defined (forest, urban, agricultural, and water body) and the percentage of each land use class in each zone defined by the intersection of the elevation and soil classes is computed. The daily series of precipitation and mean temperature for each zone were computed by taking the mean values of the interpolated values on the $5 \mathrm{~km} \times 5 \mathrm{~km}$ grids within the zones.

[15] Routing of the runoff computed by the soil moisture accounting routine to the outlet of the subwatershed is done using a lumped runoff response routine, which is conceptualized as two stacked reservoirs. The upper reservoir, which is a non linear reservoir, is directly fed by the runoff computed by the soil moisture accounting routine and its outflow simulates the direct runoff component from the upper soil zone. The lower linear reservoir is fed by percolation from the upper reservoir and its outflow simulates the base flow component of the subwatershed. The computed direct runoff and base flow components are finally transformed into a total discharge using a triangular weighting function whose base is defined by the parameter MAXBAS [Bergström, 1995].

[16] Some modifications were done to some of the routines and more components were added to the model structure so that the effect of land cover can be taken account of Hundecha [2005]. The degree day factor $C C$ is assumed to be a linear function of the daily amount of precipitation. In order to avoid an unrealistically high melt rate, an additional parameter that defines the upper bound to the degree day factor was also introduced. Rainfall or snowmelt on sealed areas are directly transformed into runoff at the outlet using the triangular function without entering the routing reservoirs. In addition, a component for infiltration excess runoff from pervious areas was added, which is modeled by defining a threshold precipitation intensity $P_{t h r}$. When the rainfall intensity exceeds this value, some portion of the rainfall in excess of this threshold value is considered to produce direct overland flow that is directly routed to the outlet of the subwatershed without entering the reservoirs of the runoff response routine. The ratio between this direct overland flow and the rainfall in excess of $P_{t h r}$ is defined as percentage of sealing during heavy rainfall $\left(\Psi_{\text {seal }}\right)$. Figure 2 shows a schematic representation of the runoff response module.

\subsection{Regionalization of Model Parameters}

[17] The parameters of the routines for the distributed components of the model are regionalized using the land use type and/or soil type. The degree day factor, $C C$, is regionalized on the basis of land use and the parameters of the soil accounting routine $(\beta$ and $F C$ ) are regionalized on the basis of soil type and land use. Regionalization of the parameters of the lumped watershed response routine is, however, carried out by identifying the spatial structures of the parameters within a space defined using watershed physiographic and climatic attributes. The rationale is to map watersheds with similar properties close to one another, no matter how they are located relative to one another geographically. A canonical correlation analysis is implemented in this work for the definition of the coordinates of the physiographic-climatic space.

[18] A canonical correlation analysis between two sets of variables basically consists of determining pairs of transformed variables, referred to as canonical variables, which are linear combinations of the original variables in each set. The weights for the linear combination are established in such a way that the correlations between the pairs are maximized (see Ouarda et al. [2001] for the details and its application in the regionalization of flood frequency). 


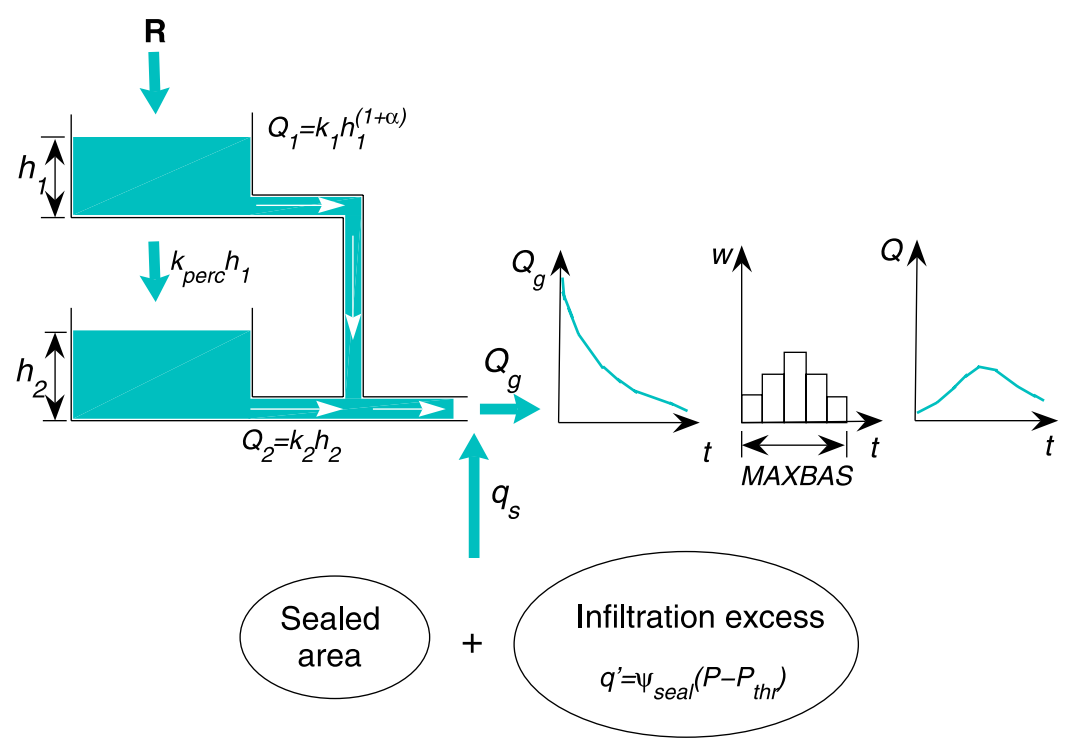

Figure 2. Schematic diagram of the runoff response module of the HBV model.

There are, in general, as many canonical pairs as the minimum number of variables in either set of the original variables. One can also determine the proportion of variance accounted for by the correlation between each pair of canonical variables. An interesting property of the canonical variables is that any pair of canonical variables in each set is uncorrelated, making the variables orthogonal to one another. This property can be exploited to define coordinate axes for the physiographic-climatic space.

[19] A canonical correlation analysis is performed between the parameters of the watershed response routine and the watershed physiographic-climatic attributes. The resulting canonical variates of the watershed physiographicclimatic attributes are then used as orthogonal bases for the definition of the coordinates of the physiographicclimatic space. The "distance" between subwatersheds is then computed as the Euclidean norm using their coordinates within the space thus defined.

[20] The physiographic attributes include: percentages of the different land use and soil classes, size and mean slope of the subwatershed, as well as a shape factor defined as the ratio between area of a subwatershed and the square of the distance from the outlet of the watershed to the farthest point in the watershed. The slope at each grid was computed using Horn's method [Horn, 1981], which computes the slope from the elevations of the neighboring eight grids by applying a weight proportional to the square of the distance of each grid from the kernel. The mean slope of a watershed is then taken as the average of the computed slopes at all grids within the watershed. Furthermore, the mean annual precipitation is used as a climate descriptor. All the attributes are standardized in order to account for the scaling effect of the different attributes.

[21] It should be noted that in addition to the proportion of the different land use and soil types as well as the mean of the watershed slope, their spatial patterns within a watershed also determine the way the watersheds respond. It would therefore be appropriate to consider the spatial patterns as well to fully characterize the similarity of watersheds in terms of their hydrological response. However, the hydrological model implemented in this work is not a fully distributed model and it does not allow incorporation of the correct spatial pattern of the watershed characteristics.

[22] The spatial structure of the model parameters in the physiographic-climatic space is modeled using a geostatistical approach. The fundamental hypothesis of basic geostatistical analysis, referred to as the intrinsic hypothesis [Journel and Huijbregts, 1978], assumes that the expected value of a regionalized variable is constant all over the domain of study and that the variance of the difference in the values of the variable corresponding to two different locations depends only on the vector separating them. This is described by a variogram function, which is defined as half of the square of the difference in the values of the parameter between two locations as a function of their separation vector. Practically, this is computed as half of the average squared difference between the values of points separated by a given vector $h$ :

$$
\gamma(h)=\frac{1}{2 N(h)} \sum_{i=1}^{N(h)}\left(x_{i}-y_{i}\right)^{2}
$$

where $N(h)$ is the number of pairs with separation vector $h$; $x_{i}$ and $y_{i}$ are the values of the corresponding pairs. Isotropic variograms are assumed in this work, in which the values of the variograms depend only on the separation distance and not on the direction.

[23] For further implementation of the variogram thus calculated in the estimation of parameters at other locations, a continuous theoretical variogram must be fitted. The fitted theoretical variogram must be positive definite and there are certain variogram forms that meet this requirement [Cressie, 1993] and the form of the fitted variogram is selected among these variograms.

[24] Once the appropriate theoretical variogram describing the spatial structure of a given parameter is estimated, the parameter value in a subwatershed whose parameter 
value is not known beforehand is estimated using a kriging technique as the weighted sum of the parameter values of "nearby" watersheds. The kriging weights are determined in such a way that the estimated value is unbiased and the estimation variance is minimized. The unbiasedness criterion requires that the spatially constant expected value of the intrinsic hypothesis holds for the estimate. The nearby watersheds are selected on the basis of their proximity in the physiographic-climatic space to the watershed for which the parameter value is being sought. They are selected using the quadrant search method. A maximum distance defined by the range of the variogram corresponding to the parameter in question is used.

\subsection{Parameter Estimation}

[25] The regional parameter estimation procedure implemented in this work follows calibration of the model for a selected set of subwatersheds simultaneously with a dual objective of maximizing the model performance and having each of the model parameters maintain a spatial structure that is described by an acceptable variogram function.

[26] The objective function used as a measure of performance of the hydrological model is a weighted form of the Nash-Sutcliffe efficiency measure, NS [Nash and Sutcliffe, 1970], which needs to be maximized:

$$
N S=1-\frac{\sum_{i=1}^{N} w(.)\left(Q_{c}\left(t_{i}\right)-Q_{0}\left(t_{i}\right)\right)^{2}}{\sum_{i=1}^{N} w(.)\left(Q_{0}\left(t_{i}\right)-\bar{Q}_{0}\right)^{2}}
$$

where $Q_{c}$ and $Q_{o}$ are the simulated and the observed discharges respectively and $\bar{Q}_{o}$ is the mean observed discharge over the simulation period ( $\mathrm{N}$ days). $w($.$) is a$ weight that gives emphasis to certain parts of the hydrograph. The observed discharge, $Q_{o}$, is used here as the weight to give progressively more weight to higher flows and improve estimation of peak flows. A general tendency of underestimation of the peak was noted in a previous study [Hundecha, 2005] using the same model in the same study area.

[27] The objective function in equation (2) indicates the performance of the model at individual subwatersheds. An objective function that is indicative of the model performance in all subwatersheds should be defined. One possibility would be to use the sum or mean value of NS at all subwatersheds as a single objective function. However, this leads to an unbalanced optimization of the model performance, since a poor performance in some subwatersheds could be offset by a good performance in others. An objective function that gives more emphasis to the subwatershed in which the model performance is the poorest is introduced to optimize the overall performance of the model in all subwatersheds:

$$
O=\sum_{m=1}^{M} N S+M \min N S
$$

where $M$ is the number of subwatersheds with discharge observation.
[28] The objective function used to evaluate whether the spatial structures of the model parameters reasonably approximate acceptable variogram functions is established in two different ways. The main difference between the two approaches lies in that the parametric form of the variogram of each of the model parameters is assumed a priori in one of the approaches while no prior assumption is made in the other approach.

[29] In the first approach, where the parametric form of the variograms is assumed a priori, the approximate form of the variogram for each of the five model parameters was set on the basis of the parameters estimated for the same study area in the work by Hundecha and Bárdossy [2004]. After performing a canonical correlation analysis between the model parameters and the watershed descriptors, a variogram was computed for each model parameter in the canonical space of the watershed descriptors. The first two canonical variates of the watershed descriptors were used to define the coordinates of the space since they account for more than $80 \%$ of the variance of the correlation and this is kept throughout the calibration process. Since the subwatersheds show no apparent clustering effect within this canonical space as shown in Figure 3, the variograms are computed using a constant lag step, which is fixed in such a way that there are at least 30 pairs of points for each lag class to compute the variogram. A lag tolerance of half the lag step is implemented to obtain enough pairs of points for each lag class.

[30] The model calibration procedure consists of estimating the model parameters and the parameters of the variograms whose forms are fixed a priori so that the performance of the model is maximized while the root mean square errors between the variogram functions and the computed empirical variograms are minimized. The problem is therefore a multiobjective optimization problem. The optimization was performed with the aim of simultaneously maximizing the objective function in equation (3) and minimizing the normalized form of the root mean square error between the variogram functions and the empirical variograms of all the model parameters. Since this is basically a multi objective optimization problem, the objective functions measuring the model performance and the fit of the variograms are combined into a single objective function. This was done by subtracting the sum of the normalized root mean square error of the variogram fit corresponding to each of the five model parameters from the objective function given in equation (3). The objective function in equation (3) was divided by $2 M$ to bring it to the same scale as the normalized mean square errors of the variogram fit. The objective is then to maximize the resulting objective function.

[31] Prior assumption of the parametric form of the variograms imposes undesirable constraints on the model parameters and may not lead to the best solution in estimating the variogram functions. A second approach, in which no prior assumption of the parametric form of the variograms is made, is implemented to estimate the model parameters. In this method, the model parameters are estimated in such a way that the continuity of the model parameters within the canonical space of the watershed descriptors is ensured by minimizing the cumulative variance of the parameters separated by different distances 


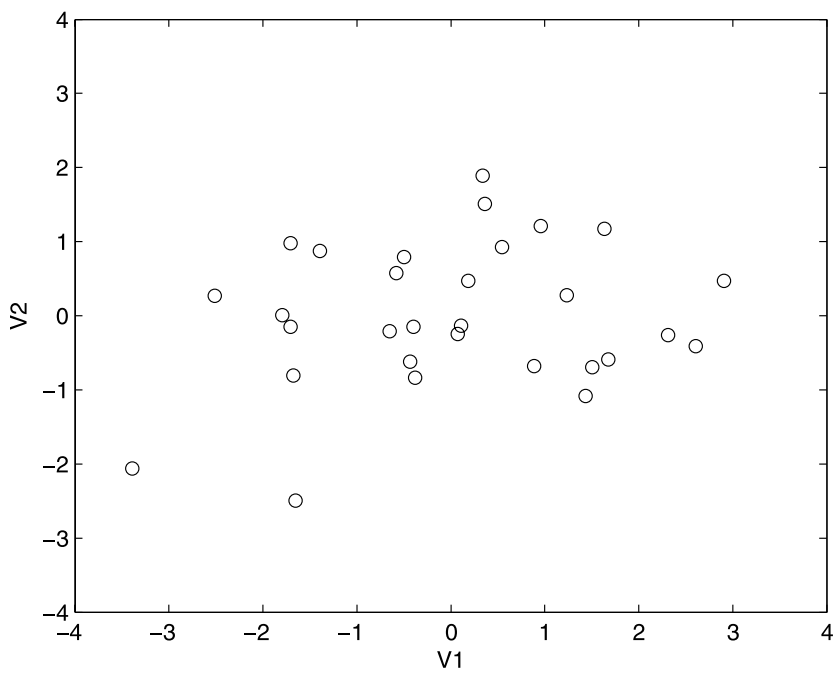

Figure 3. Locations of subwatersheds of the calibration set within the physiographic-climatic canonical space defined using the first two canonical variables of the physiographic-climate attributes of the watersheds.

while the variance increases monotonically with separation distance. This ensures that the difference in the parameter values continuously increases with increasing distance between them in the watershed attributes' space. Simultaneously, performance of the hydrological model is maximized. To achieve this, an approach similar to the one followed by Bárdossy et al. [2005] for the prediction of watershed discharge characteristics from watershed properties is implemented. A function that expresses the increase in the variance of the parameter value as a function of the separation distance is defined in a nonparametric way as

$$
G_{B}(p)=\frac{1}{\mathrm{~N}(p)} \sum_{\left\|x_{i}-x_{j}\right\|<d(p)}\left(y_{i}-y_{j}\right)^{2}
$$

where $p$ is the proportion of pairs of watersheds with separation distance in the canonical space less than $d(p)$ and $\mathrm{N}(p)$ is the corresponding actual number of pairs; $x_{i}$ and $x_{j}$ are the location vectors of watersheds $i$ and $j$ respectively in the canonical space; $y_{i}$ and $y_{j}$ are the parameter values of watersheds $i$ and $j$ respectively.

[32] To ensure continuity of the parameter values, one can minimize $G_{B}\left(p_{0}\right)$ for a selected $p_{0}<1$, where $d\left(p_{0}\right)$ is the limiting distance in the canonical space of the neighboring watersheds used for estimation of parameters using kriging. However, because of the possible uneven distribution of the watersheds in the canonical space, this limiting distance may vary for different watersheds, making selection of an appropriate $p_{0}$ difficult. Thus one can alternatively consider minimizing the integral of the $G_{B}(p)$ versus $p$ curve up to a limiting proportion $p^{*}$ :

$$
G=\int_{0}^{p^{*}} G_{B}(p) d p \rightarrow \min
$$

where $p^{*}=n_{p} / n, n_{p}$ is the number of neighboring watersheds used for estimation of parameters using kriging and $n$ is the total number of watersheds in the calibration set. Practically, equation (5) can be simplified by dividing $p^{*}$ into a number of portions $(J)$ as

$$
G=\sum_{j=1}^{J} G_{B}\left(p_{j}\right)
$$

where $p_{J}=p^{*}$. The monotonicity of the variogram function is insured if

$$
G_{B}\left(p_{i}\right)<G_{B}\left(p_{j}\right) \text { for } i<j
$$

A penalty function $W$ is introduced that is used as a multiplier to the objective function of equation (6) if the monotonicity condition is not met:

$$
W=\prod_{j=2}^{J} \max \left(1, \frac{G_{B}\left(p_{j-1}\right)}{G_{B}\left(p_{j}\right)}\right)
$$

For a detailed discussion of the formulation of the procedure, one is referred to Bárdossy et al. [2005].

[33] The resulting parameter estimation problem is a multiobjective optimization problem requiring maximizing the objective function of equation (3) and minimizing five functions of the form given in equation (6) (one for each of the five model parameters). The objective function in equations (3) and (6) were reduced into a single objective function as the sum of the five objective functions of equation (6) minus the objective function in equation (3), which needs to be minimized. In order to bring the two set of objective functions to a similar scale, the objective function in equation (3) is divided by $2 M$. Once the optimum parameters are estimated, the best variogram function corresponding to each of the model parameters is then fitted to the empirical variogram calculated for each of the parameters within the canonical space of the watershed descriptors using the least squares approach. In both approaches, simulated annealing [Kirkpatrick et al., 1983] is implemented to estimate the optimum regional parameters.

\section{Results and Discussion}

\subsection{Calibration}

[34] The regional model calibration was performed on the basis of simulating daily discharge values for the period 1983 to 1988 . The subwatersheds selected to constitute the calibration set reflect a wide range of each of the watershed attributes used to regionalize the model parameters and they are selected from geographically different regions within the study area. Table 1 shows the ranges of the different watershed attributes in the calibration and validation set of subwatersheds. Note that some of the watershed attributes in the validation set are outside their corresponding range in the calibration set. This enables us to validate the possibility of extrapolation of the model parameter values using the regional relationship established in the calibration set.

[35] Figure 3 shows the empirical and the corresponding theoretical variograms pertaining to each of the parameters of the lumped runoff response routine, which were obtained after the regional model calibration using the parametric approach. Also Table 2 shows the parameters of the fitted 
Table 1. Ranges of the Watershed Attributes Used for Regionalization of Model Parameters in the Calibration and Validation Set of Subwatersheds

\begin{tabular}{|c|c|c|c|c|}
\hline \multirow[b]{2}{*}{ Watershed Attribute } & \multicolumn{2}{|c|}{ Calibration Set } & \multicolumn{2}{|c|}{ Validation Set } \\
\hline & Maximum & Minimum & Maximum & Minimum \\
\hline \multicolumn{5}{|l|}{ Land use class } \\
\hline Forest, \% & 69.2 & 14.6 & 76.6 & 10.1 \\
\hline Urban, \% & 34.0 & 8.0 & 49.5 & 8.3 \\
\hline Agricultural, \% & 69.7 & 14.3 & 73.2 & 5.6 \\
\hline Water bodies, \% & 1.1 & 0.0 & 1.2 & 0.0 \\
\hline \multicolumn{5}{|l|}{ Soil type } \\
\hline Lithosol, \% & 18.7 & 0.0 & 16.3 & 0.0 \\
\hline Ranker, \% & 18.0 & 0.0 & 13.1 & 0.0 \\
\hline $\begin{array}{l}\text { Gleysol plus } \\
\text { Rendzina, \% }\end{array}$ & 50.3 & 0.0 & 22.7 & 0.0 \\
\hline Cambisol, \% & 87.9 & 8.6 & 100.0 & 0.0 \\
\hline Luvisol, \% & 67.4 & 1.8 & 87.8 & 0.0 \\
\hline Podzol, \% & 31.7 & 0.0 & 15.0 & 0.0 \\
\hline Mean slope, $\%$ & 3.75 & 0.6 & 3.51 & 0.44 \\
\hline Shape factor & 1.35 & 0.13 & 1.33 & 0.18 \\
\hline Area, $\mathrm{km}^{2}$ & 2879.0 & 507.0 & 2009.0 & 107.0 \\
\hline $\begin{array}{l}\text { Mean annual } \\
\text { precipitation, } \mathrm{mm}\end{array}$ & 1055 & 628 & 1244 & 1244 \\
\hline
\end{tabular}

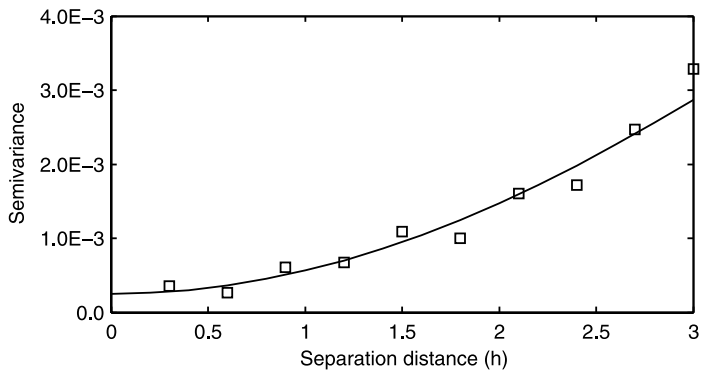

a) Parameter $\alpha[-]$; Gaussian

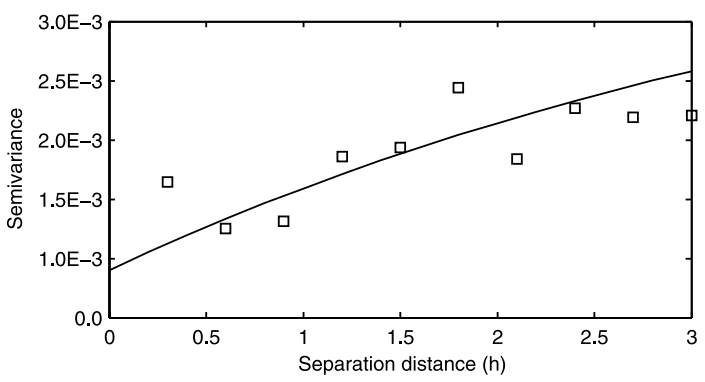

c) Parameter $k_{2}\left[1000 x d a y^{-1}\right]$; Exponential variogram functions for each model parameter. One can see from Figure 4 that all parameters show a marked spatial structure in the canonical space, which is an indication that the parameters are continuous over the canonical space. Parameters of the upper reservoir and the percolation parameter show a spatial structure which can be modeled accurately using a Gaussian variogram. On the other hand, the recession constant for the lower reservoir shows a structure that is described by an exponential variogram while the smoothing function, MAXBAS, shows a structure that is best described by a spherical variogram. Indeed, as noted earlier in connection with the parametric approach, the form of the variogram for each parameter was set a priori and the objective of the model calibration was to find parameters which give the best model performance and at the same time the best fit to the assumed variograms, which is measured by the sum of the squared errors. It should also be noted that a nugget effect is added to account for a possible discontinuity of the variograms at the origin.

[36] Figure 5 shows the empirical and the fitted theoretical variograms for each of the model parameters in the canonical space after the parameters are estimated using the nonparametric approach. Like in the parametric approach, in this approach too, the parameters show continuity in the

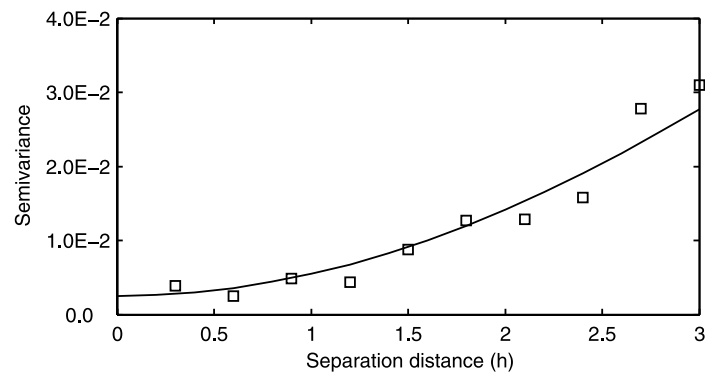

b) Parameter $\mathrm{k}_{1}\left[100 \mathrm{xday}^{-1}\right]$; Gaussian

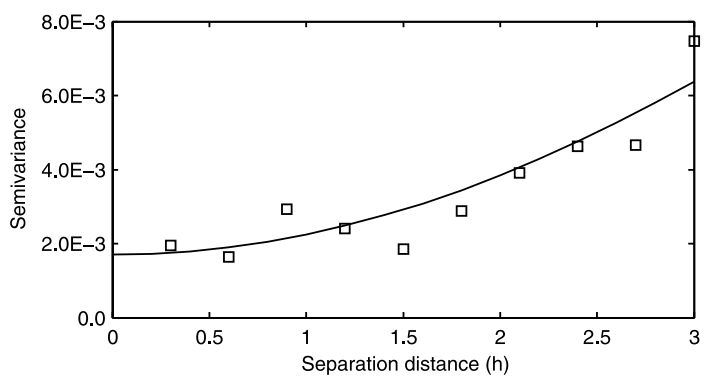

d) Parameter $\mathrm{k}_{\text {perc }}\left[100 \mathrm{xday}^{-1}\right]$; Gaussian

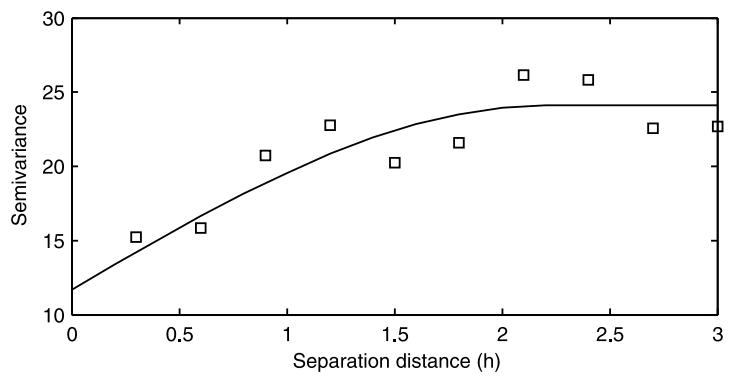

e) Parameter MAXBAS [hours] ; Spherical

Figure 4. Experimental and fitted theoretical variograms for the parameters of the runoff response routine estimated using the parametric approach. 
Table 2. Parameters of the Variogram Functions Pertaining to the Different Model Parameters

\begin{tabular}{lccccc}
\hline \multirow{2}{*}{ Parameter } & Method & $\begin{array}{c}\text { Variogram } \\
\text { Model }\end{array}$ & Nugget & Sill & Range \\
\hline \multirow{2}{*}{$\alpha$} & parametric & Gaussian & $2.5 \times 10^{-4}$ & 0.016 & 7.22 \\
\multirow{2}{*}{$\mathrm{k}_{1}$} & nonparametric & Gaussian & $2.5 \times 10^{-4}$ & 0.013 & 7.02 \\
& parametric & Gaussian & $2.5 \times 10^{-3}$ & 0.135 & 8.062 \\
$\mathrm{k}_{2}$ & nonparametric & Gaussian & $5 \times 10^{-4}$ & 0.24 & 9.09 \\
& parametric & exponential & $9 \times 10^{-4}$ & $3.4 \times 10^{-3}$ & 4.4 \\
$\mathrm{k}_{\text {perc }}$ & nonparametric & Gaussian & $7 \times 10^{-5}$ & 0.031 & 9.96 \\
\multirow{2}{*}{ MAXBAS } & parametric & Gaussian & $1.7 \times 10^{-3}$ & 0.045 & 7.42 \\
& nonparametric & Gaussian & $6 \times 10^{-4}$ & 0.0721 & 9.79 \\
& parametric & Spherical & 11.7 & 12.4 & 2.2 \\
& nonparametric & Gaussian & 3.70 & 195.51 & 9.54 \\
\hline
\end{tabular}

canonical space. However, one can notice that the best theoretical variograms fitted to all of the parameters are Gaussian. In fact, these are more natural patterns of variability since no prior assumption was made about the form of the variograms. Besides, because of the minimization of the local variance, the nugget effects (which represent the variance of the variable) in all the variograms are lower compared to that of the parametric approach.

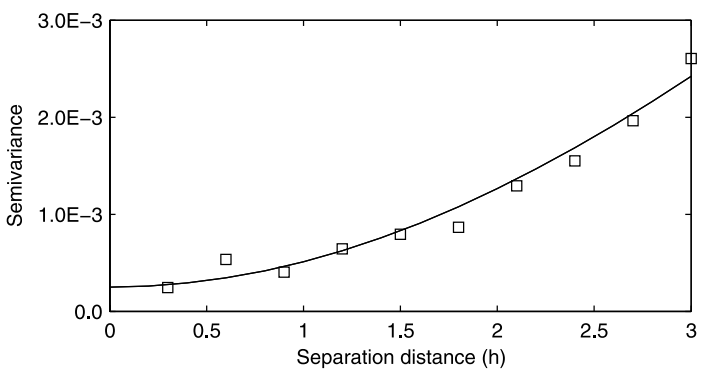

a) Parameter $\alpha[-]$; Gaussian

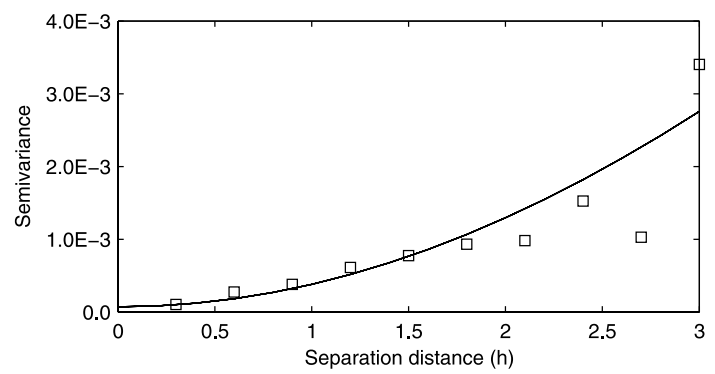

c) Parameter $k_{2}\left[1000 x d a y{ }^{-1}\right]$; Gaussian
[37] Under the stationarity assumption, the variograms normally attain a sill at a certain separation distance (the range of the variogram), which defines a separation distance beyond which the parameters are not correlated anymore. As shown in Figures 4 and 5, however, most of the variograms do not show this behavior, at least within the range of separation distances covered by the calibration set of subwatersheds. This is an indication that there could be either a spatial nonstationarity in the parameters or that the range could be beyond those observed. Since the range of variability of the watershed descriptors within the calibration set of subwatersheds doesn't span the whole spectrum of the variation of the descriptors, the latter case was assumed in this work and estimation of parameters in the other subwatersheds was done within the framework of spatial stationarity. In addition, an investigation was made on the estimated model parameters whether they show any trend within the canonical space of the watershed physiographicclimate space. None of the parameters show a significant trend. Figure 6 shows, as an example the variation of two of the model parameters $\left(\alpha\right.$ and $\mathrm{k}_{1}$ ) estimated using the nonparametric approach against distance of the watersheds from the origin of the canonical space.

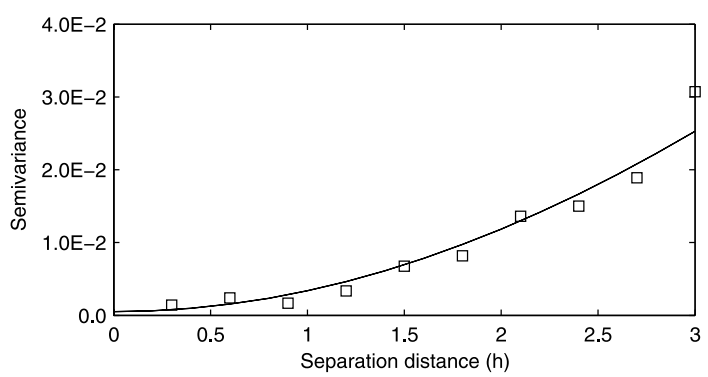

b) Parameter $\mathrm{k}_{1}\left[100 \mathrm{xday}^{-1}\right]$; Gaussian

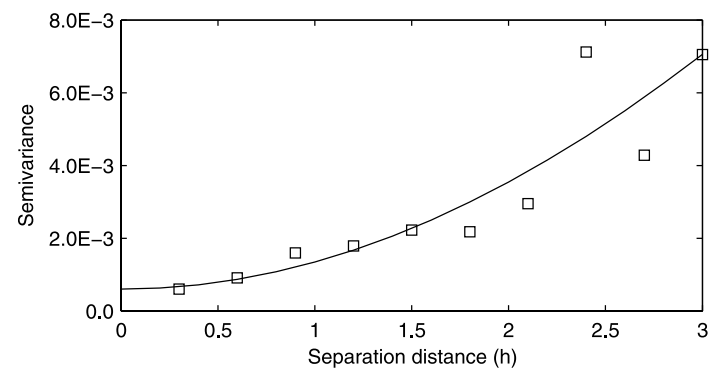

d) Parameter $k_{\text {perc }}\left[100 \mathrm{xday}^{-1}\right]$; Gaussian

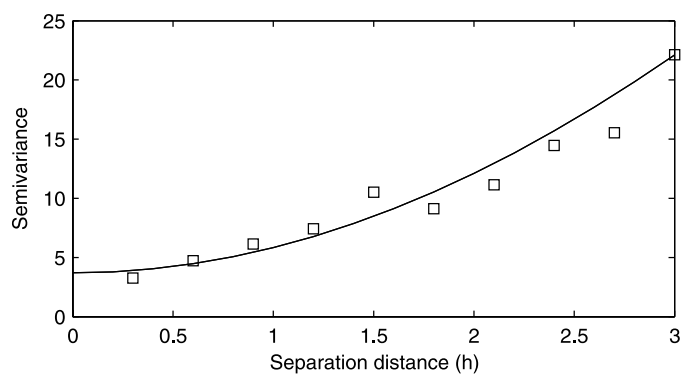

e) Parameter MAXBAS [hours] ; Gaussian

Figure 5. Experimental and fitted theoretical variograms for the parameters of the runoff response routine estimated using the nonparametric approach. 

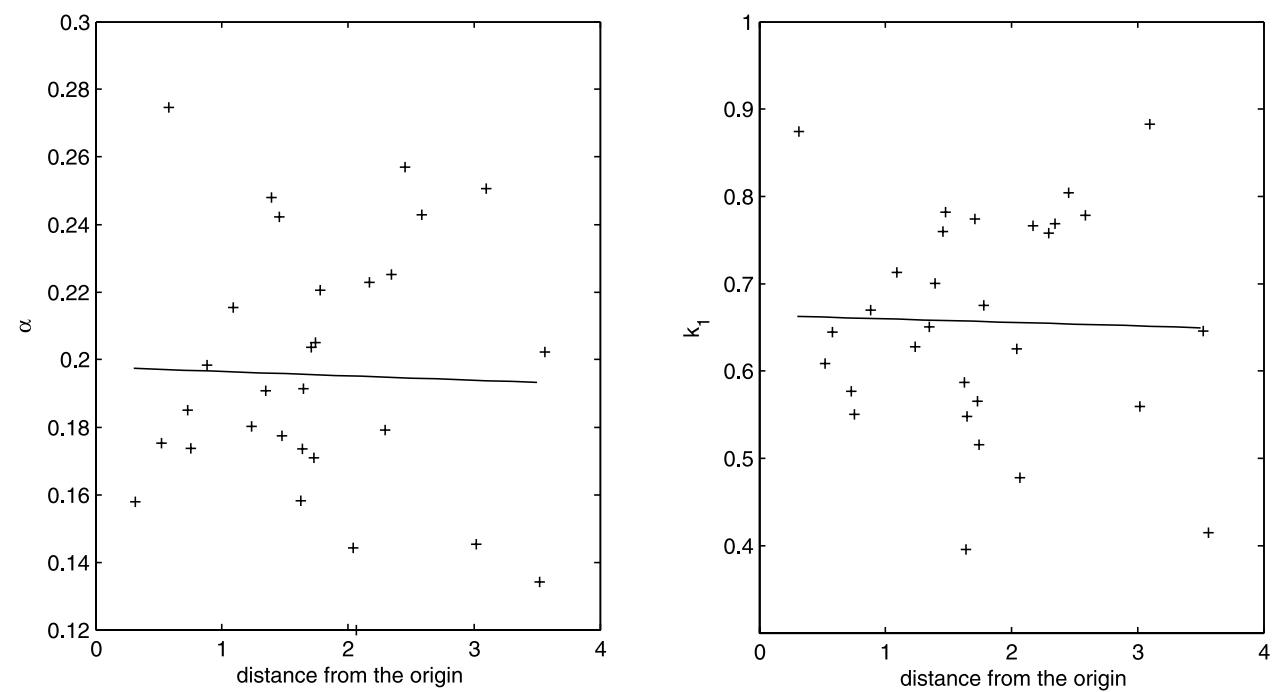

Figure 6. Variation of two of the model parameters against distance from the origin of the canonical space of the watershed physiographic-climate attributes.

[38] The model performance in the calibration set of subwatersheds during the calibration period, as evaluated by the $N S$ value, ranges between 0.70 and 0.93 with a mean value of 0.86 when the parametric approach is used. When the nonparametric approach is used the $N S$ value ranges between 0.71 and 0.93 , with a mean value of 0.87 . The subwatersheds with the maximum and minimum $N S$ values are the same in both approaches and indeed, there is only a slight difference in model performance between the two approaches in all subwatersheds. Indeed, the minimum
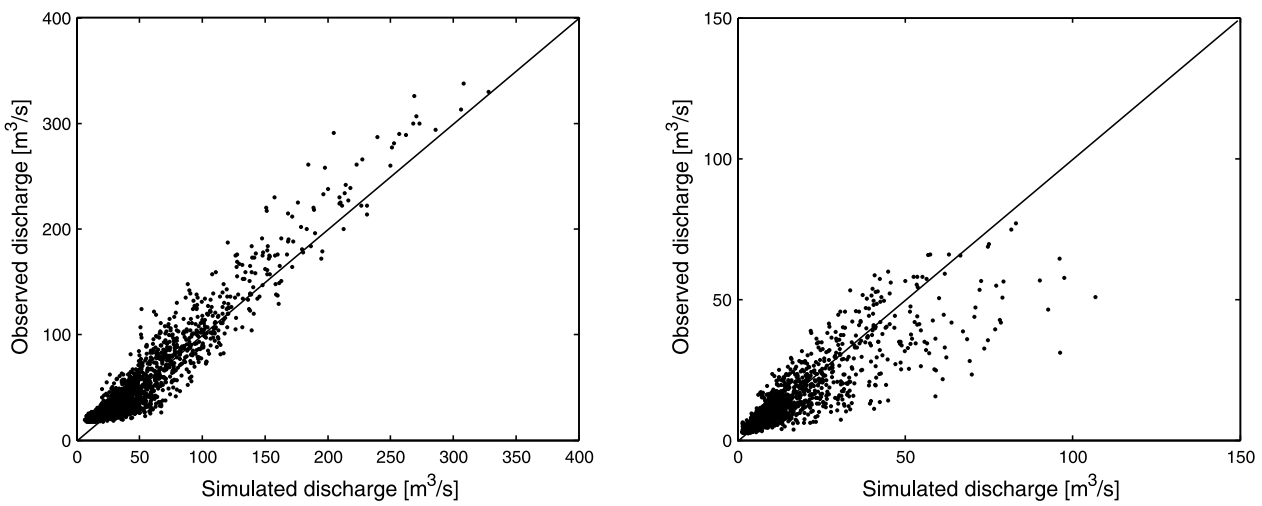

a) Schermbeck (Lippe)
Parametric (NS $=0.93$ )

b) Hannau (Main)

Parametric (NS $=0.70)$
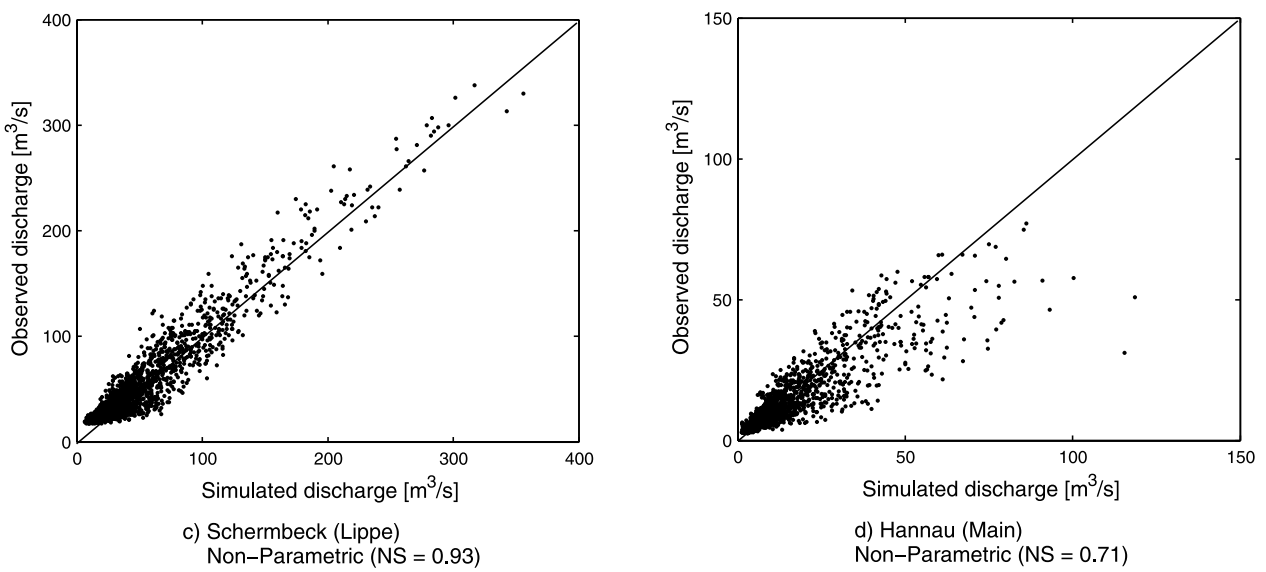

Figure 7. Scatterplots of the simulated and the observed daily discharges over the model calibration period at gauges where the model performances are the best and the worst. 
Table 3. Spearman's Rank Correlation Coefficients of Estimated Model Parameters With Watershed Attributes ${ }^{\mathrm{a}}$

\begin{tabular}{|c|c|c|c|c|c|c|}
\hline $\begin{array}{l}\text { Watershed } \\
\text { Attribute }\end{array}$ & Method & $\alpha$ & $\mathrm{k}_{1}$ & $\mathrm{k}_{2}$ & $\mathrm{k}_{\text {perc }}$ & MAXBAS \\
\hline \multirow[t]{2}{*}{ Percent forest } & parametric & 0.16 & 0.31 & 0.21 & 0.7 & 0.42 \\
\hline & nonparametric & -0.11 & 0.17 & 0.37 & 0.44 & 0.17 \\
\hline \multirow[t]{2}{*}{ Percent urban area } & parametric & 0.42 & -0.08 & 0.18 & -0.11 & -0.35 \\
\hline & nonparametric & 0.49 & 0.17 & 0.09 & -0.07 & 0.02 \\
\hline \multirow[t]{2}{*}{ Percent agricultural area } & parametric & -0.61 & -0.68 & 0.05 & -0.51 & 0.46 \\
\hline & nonparametric & -0.48 & -0.36 & -0.34 & -0.38 & 0.06 \\
\hline \multirow[t]{2}{*}{ Percent water body } & parametric & -0.21 & -0.15 & 0.06 & -0.17 & 0.12 \\
\hline & nonparametric & 0.11 & -0.20 & -0.14 & -0.28 & 0.29 \\
\hline \multirow[t]{2}{*}{ Percent Lithosol } & parametric & -0.69 & -0.53 & -0.22 & -0.69 & 0.12 \\
\hline & nonparametric & -0.38 & -0.43 & -0.04 & -0.43 & 0.26 \\
\hline \multirow[t]{2}{*}{ Percent Ranker } & parametric & 0 & -0.02 & -0.54 & 0.01 & 0.05 \\
\hline & nonparametric & -0.09 & -0.17 & -0.12 & 0.13 & 0.09 \\
\hline \multirow[t]{2}{*}{ Percent Gleysol } & parametric & -0.37 & -0.3 & 0.02 & -0.19 & -0.04 \\
\hline & nonparametric & -0.38 & -0.15 & -0.02 & -0.38 & 0.11 \\
\hline \multirow[t]{2}{*}{ Percent Cambisol } & parametric & 0.9 & 0.92 & 0.18 & 0.78 & -0.29 \\
\hline & nonparametric & 0.73 & 0.77 & 0.06 & 0.68 & -0.22 \\
\hline \multirow[t]{2}{*}{ Percent Luvisol } & parametric & 0.16 & -0.33 & 0.17 & -0.44 & 0.07 \\
\hline & nonparametric & -0.61 & -0.57 & 0.31 & -0.47 & -0.07 \\
\hline \multirow[t]{2}{*}{ Percent Podzol } & parametric & -0.14 & -0.21 & -0.5 & -0.33 & 0.27 \\
\hline & nonparametric & -0.04 & 0.01 & -0.12 & -0.32 & -0.03 \\
\hline \multirow[t]{2}{*}{ Area } & parametric & -0.58 & -0.66 & 0.05 & -0.33 & 0.73 \\
\hline & nonparametric & -0.5 & -0.54 & 0.24 & -0.31 & 0.25 \\
\hline \multirow[t]{2}{*}{ Mean slope } & parametric & 0.58 & 0.51 & 0.48 & 0.29 & -0.52 \\
\hline & nonparametric & 0.38 & 0.28 & 0.51 & 0.46 & -0.41 \\
\hline \multirow[t]{2}{*}{ Shape factor } & parametric & 0.18 & 0.15 & 0.15 & 0.09 & -0.12 \\
\hline & nonparametric & -0.1 & 0.14 & -0.55 & -0.02 & 0.21 \\
\hline \multirow[t]{2}{*}{ Mean annual precipitation } & parametric & 0.55 & 0.5 & 0.1 & 0.4 & 0.14 \\
\hline & nonparametric & 0.63 & 0.54 & -0.09 & 0.19 & 0.17 \\
\hline
\end{tabular}

${ }^{\mathrm{a}}$ Correlations at $5 \%$ significance level are shown in bold.

value can be treated as an outlier, as the NS value in more than $80 \%$ of the subwatersheds exceeds 0.85 in both approaches. The minimum value pertains to one of the subwatersheds in the Main subbasin. Figure 7 shows scatter diagrams of the daily simulated flow using parameters estimated through both approaches against the observed over the whole calibration period for two of the subwatersheds in the calibration set in which the model performances are the best and the worst. As shown in Figures $7 \mathrm{~b}$ and $7 \mathrm{~d}$, despite the good performance of the model in estimating low flows, the peaks are highly overestimated. This is contrary to the general tendency of the model to underestimate the peak flow and there could be a problem with measurement of the peak. In the other subwatersheds, the mean flow is generally well estimated with slight underestimation in some and slight overestimation in the others. The peak flow is, however, generally a little underestimated in most of the subwatersheds.

\subsection{Relationships Between Model Parameters and Watershed Attributes}

[39] Table 3 shows the Spearman's rank correlation coefficients between the watershed attributes and the model parameters estimated using both approaches. The parameter $\alpha$ shows a significant positive correlation with the percentage of urban area, percentage of Cambisol, mean watershed slope, and mean annual precipitation in both methods. On the other hand, it shows a significant negative correlation with size of the watershed, percentage of agricultural area, and percentage of Lithosol and Gleysol. This parameter controls the fast response of the watershed and the relationship suggests that an increase in urban area leads to a faster response while more agricultural land use results in a decline in the fast response of a watershed. There is however, no significant correlation between the fast response of a watershed and percentage of forest areas. It is also interesting to note that wetter watersheds tend to respond faster. On the other hand, the result suggests that larger watersheds respond slowly. The other parameter, $\mathrm{k}_{1}$, which also controls the fast response of a watershed shows similar correlation pattern with the watershed attributes except with the percentages of urban area and Gleysol. In both methods, the correlation between the parameter and the percentage of urban area is not significant.

[40] Parameter $\mathrm{k}_{2}$, which controls the slower base flow component shows a less consistent correlation pattern with the watershed attributes for the two methods, which makes it difficult to make a general conclusion about their relationship. The only watershed descriptor both methods consistently suggest is related to this parameter is mean watershed slope. They both suggest an increase in the slow response of the watershed with watershed slope. While the parametric approach resulted in a significant correlation of the parameter with mean slope of the watershed and some of the soil types, the nonparametric approach indicated a significant correlation with percentage of forest cover, mean slope of the watershed, and the watershed's shape factor.

[41] The parameter that controls deep percolation, $\mathrm{k}_{\text {perc }}$, on the other hand shows significant correlations with some of the soil types and the percentage of forest cover. The relationship suggests that more percolation takes place in watersheds mainly coved by Cambisol and less in watersheds mainly coved by Lithosol and Luvisol. Similarly, the result suggests that forest cover results in more percolation. 


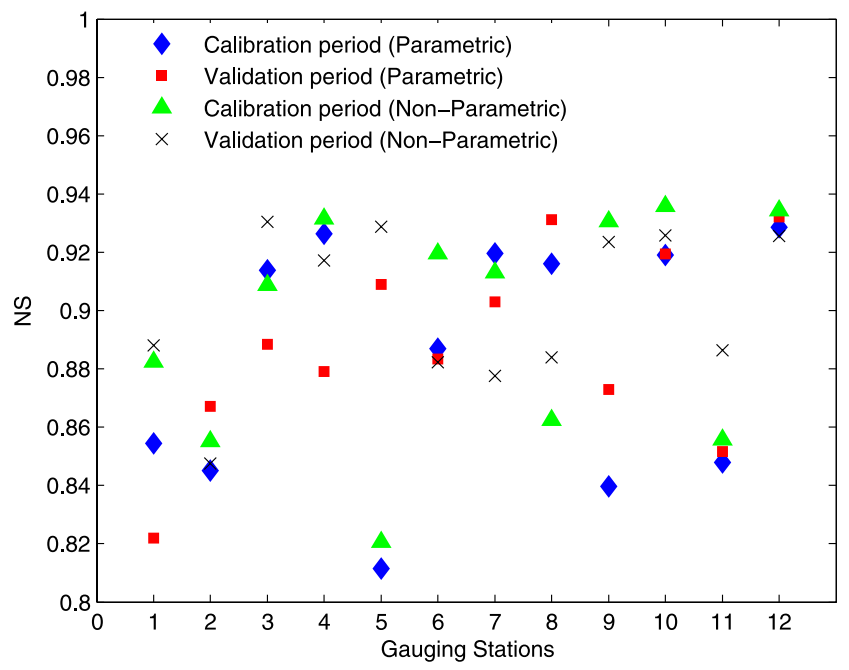

Figure 8. Comparison of the model performance measure in the calibration set of subwatersheds for which enough records are available for validation during the model calibration and validation periods.

One can also note from Table 3 that the parametric approach suggests that an increase in urban area reduces the amount of percolation.

[42] For parameter MAXBAS, both approaches indicate a significant negative correlation with the mean watershed slope. The parameter controls the time required to drain the watershed and the degree of attenuation of the runoff resulting from an event in a watershed. The negative relationship with the watershed slope is therefore what one would expect. One would also expect a positive correlation of the parameter with the watershed size. However, only the parametric approach resulted in a significant positive correlation of the parameter with the watershed size. The parametric approach further suggests that forest and agricultural land use also have a tendency to attenuate the runoff and increase the drainage time.

\subsection{Validation of the Regional Estimation Scheme}

[43] Validation of the parameter regionalization scheme was performed both in time and space. Validation in time is performed via split-sample testing. In addition to making use of the data that is not used for model calibration to evaluate the performance of the calibrated model, one can evaluate the possibility of extrapolating model parameters estimated under a given range of climate variability to a possibly different range of variability. The model validation experiment was done for the period 1989 to 1995. This period is generally warmer and drier than the calibration period, with the mean daily temperature between $0.83^{\circ} \mathrm{C}$ and $1{ }^{\circ} \mathrm{C}$ higher and the mean daily precipitation between $3.5 \%$ and $10 \%$ lower in different subwatersheds.

[44] The NS value during the validation period in the calibration set of subwatersheds ranges between 0.82 and 0.93 for the parametric approach while it varies between 0.84 and 0.93 for the nonparametric approach. Indeed, not all the subwatersheds have observations for the entire validation period and the values reported here are only for those subwatersheds with observations over the whole validation period. During the calibration period, the value in these subwatersheds ranges between 0.81 and 0.93 . Figure 8 shows a comparison of the model performance between the calibration and validation periods. It is interesting to note that in some subwatersheds, the model performance over the validation period for both approaches is even better than the corresponding performance in the calibration period. This is not, however, the general tendency and in some subwatersheds the performance is, as would be expected, lower. There is a slight difference in model performance in the calibration set of subwatersheds between the two approaches during the validation period. However, the differences are not systematic and nothing can be said about the superiority of one of the approaches over the other.

[45] Validation of the regionalization scheme in space is performed by applying the regional relationship between model parameters and watershed descriptors to subwatersheds that were not used in model calibration. Indeed, this is the most important part of the validation exercise for the regionalization of the parameters, since all the model parameters are estimated on the basis of the established regional relationship using only the watershed descriptors. The model performance evaluation was made separately for the calibration and validation periods used in the calibration set of subwatersheds so that comparison of the performance of the model in the two sets can be carried out over similar periods of model simulation.

[46] The performance of the regionalized model in the validation set during both periods is very similar to the corresponding model performance in the calibration set. The two approaches also show competitive performance skills in the validation set. Figure 9 presents comparison of the $N S$ values of the two approaches between the model calibration and the validation periods at different gauges in the validation set where there are full discharge records during the validation period (1989-1995). Both the mean daily runoff and the peak discharges are well estimated in most of the validation subwatersheds despite the general tendency of the model to underestimate the peak. Interestingly, the peak discharges are even better estimated in most of the validation subwatersheds than in the calibration set.

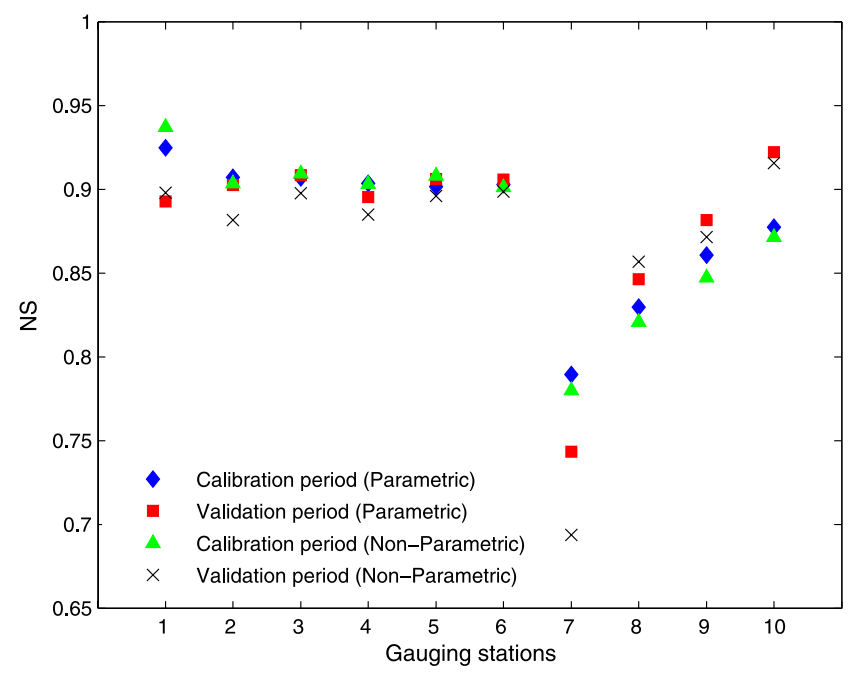

Figure 9. Comparison of the model performance measure in some of the validation set of subwatersheds over the calibration and validation periods used in the calibration set. 

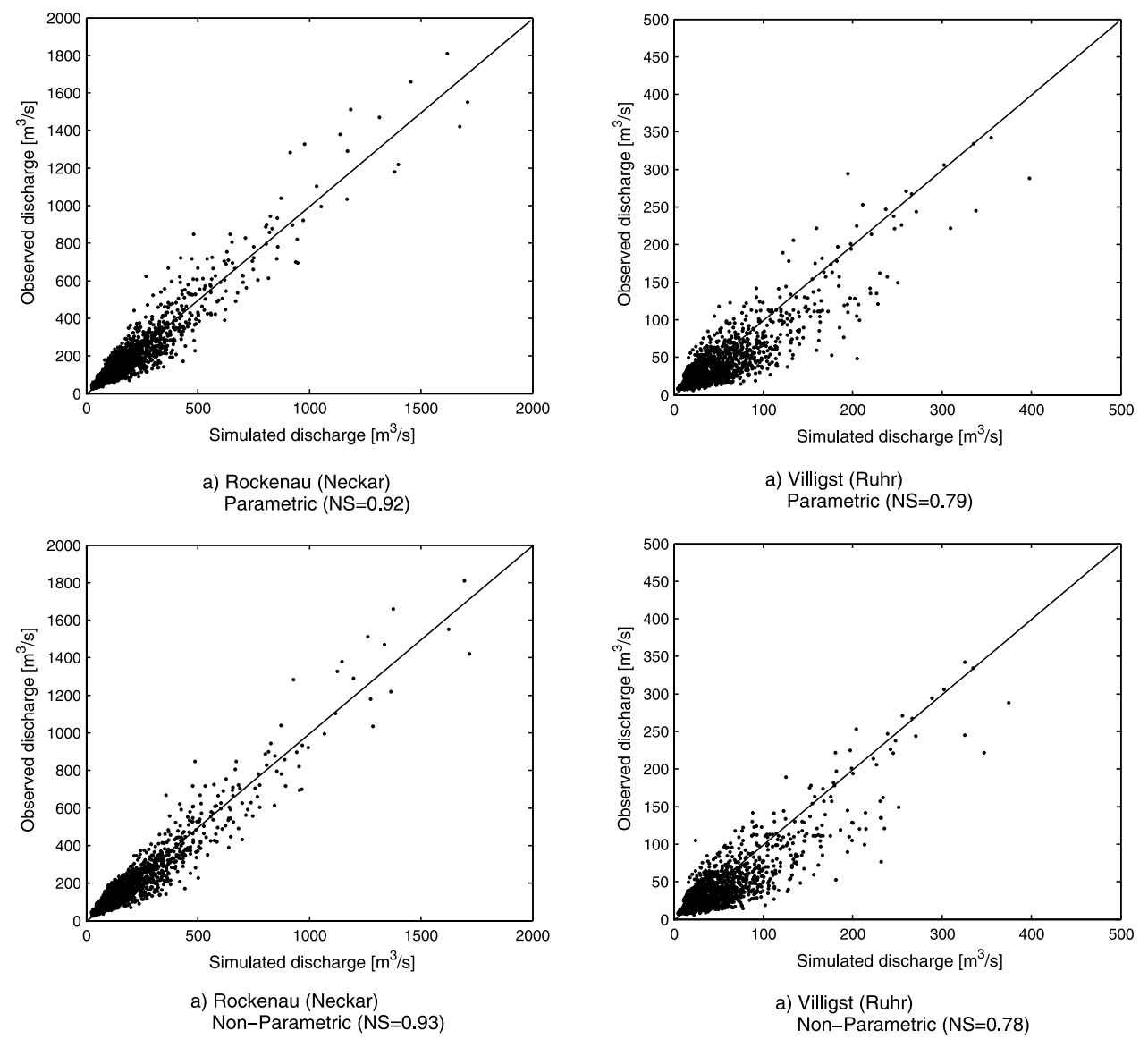

Figure 10. Scatterplots of the simulated and the observed daily discharges at two of the gauges in the validation set of subwatersheds over the model calibration period.

Figure 10 shows the scatterplots of the observed and the modeled daily runoff at two gauges of the validation set where the $N S$ values are the maximum and the minimum respectively over the model calibration period.

[47] One important outcome of the validation experiment is that the results suggest the possibility of extrapolation of the model parameters for watershed descriptors outside the range within which the regional relationships were established. As shown in Table 1, the range of the percentages of most of the land use classes in the validation set of subwatersheds is slightly wider than the corresponding range in the calibration set and yet the model performance in both sets is comparable. For instance, the NS value obtained using both approaches in the validation subwatershed which has the largest forest cover is around 0.9 during the period over which the model calibration was done, which is slightly higher than the average value obtained in the calibration set during model calibration (0.87). It should be noted, however, that this extrapolative nature might only be applicable for slight deviations of the watershed descriptors from their range in the calibration set and it could be risky to apply it for large deviations. Further efforts should be dedicated to investigating this point.

[48] In general, on the basis of the NS value, the regionalization scheme presented in this work has resulted in a slight improvement of performance compared to the scheme that is based on a linear relationship between the model parameters and the watershed descriptors reported in
Hundecha and Bárdossy [2004]. Indeed, most of the improvements were noted in the validation set.

\section{Summary and Conclusions}

[49] A regional estimation technique for parameters of one of the widely used conceptual rainfall-runoff models was developed and tested. The technique was developed with the aim of accounting for the nonlinearity of the relationship between the lumped model parameters and a set of watershed descriptors. This was done by making use of a geostatistical technique for the analysis of the spatial structure of the model parameters within a space defined with coordinates derived from the canonical variables of the watershed descriptors obtained through a canonical correlation analysis between the model parameters and the watershed descriptors. The implemented approach tries to identify the model parameters for a set of subwatersheds that maximize the model performance in all subwatersheds while maintaining a spatial structure within the watershed physiographic-climatic space that is amenable to a geostatistical analysis. Two different approaches were implemented to achieve this goal.

[50] A well-defined spatial structure was found for each of the lumped model parameters that can be described by a valid variogram function while a fairly uniform and acceptable model performance was achieved in the subwatersheds used to derive the regional model parameters. Although the 
two approaches yielded comparable results in terms of performance of the hydrological model, the nonparametric approach resulted in the best fit between the empirical and theoretical variograms pertaining to all the model parameters. This is due to the fact that no prior assumption needs to be made about the form of the variogram and therefore less constraint is imposed on the parameters, leading to a more natural spatial structure.

[51] Parameters for subwatersheds that were not used to derive the spatial structure of the parameters were estimated by interpolation within the canonical space from the calibrated parameters using ordinary kriging and the variograms obtained for each of the parameters. Indeed, this provides a more natural way of transferring parameters from gauged watersheds to ungauged watersheds since kriging assigns more weights to parameters of the nearby watersheds within the physiographic-climatic space. The performance of the model run with parameters thus estimated was comparable to its corresponding performance in the calibration set of subwatersheds. This suggests the potential use of the approach to estimate model parameters in ungauged watersheds using a set of watershed descriptors. Furthermore, the results suggest the validity of the regional relationship for extrapolation of the model parameters when some of the watershed descriptors lie slightly outside the range used to derive the relationship. This is, indeed, a desirable feature for the assessment of the impact of changes in watershed attributes, such as land use. However, this extrapolative nature should be interpreted with care for large deviation of the watershed properties from the range of their variability used to establish the relationship.

[52] Acknowledgments. The financial support provided by the Natural Sciences and Engineering Research Council of Canada (NSERC) and the "Centre d'Études Nordiques" of Laval University is gratefully acknowledged. The authors wish to thank Andre St-Hilaire for reading the manuscript and providing helpful suggestions. Thanks are also due to K. Chokmani for his assistance. We also thank Erwin Zehe and two anonymous reviewers for their helpful comments.

\section{References}

Abdulla, F. A., and D. P. Lettenmaier (1997), Development of regional parameter estimation equations for a macroscale hydrologic model, J. Hydrol., 197, 230-257.

Ahmed, S., and G. deMarsily (1987), Comparison of geostatistical methods for estimating transmissivity using data on transmissivity and specific capacity, Water Resour. Res., 23(9), 1717-1737.

Bárdossy, A., G. G. S. Pegram, and L. Samaniego (2005), Modeling data relationships with a local variance reducing technique: Applications in hydrology, Water Resour. Res., 41, W08404, doi:10.1029/ 2004WR003851.
Bergström, S. (1995), The HBV model, in Computer Models of Watershed Hydrology, edited by V. P. Singh, pp. 443-476, Water Resour. Publ., Littleton, Colo.

Beven, K. J., and J. Freer (2001), Equifinality, data assimilation, and uncertainty estimation in mechanistic modelling of complex environmental systems, J. Hydrol., 249, 11-29.

Chokmani, K., and T. B. M. J. Ouarda (2004), Physiographical space-based kriging for regional flood frequency estimation at ungauged sites, Water Resour. Res., 40, W12514, doi:10.1029/2003WR002983.

Cressie, N. A. C. (1993), Statistics for Spatial Data, 900 pp., John Wiley, New York.

Duan, Q. S., S. Sorooshian, and V. Gupta (1992), Effective and efficient global optimisation for conceptual rainfall-runoff models, Water Resour. Res., 28, 1015-1031.

Fernandez, W., R. M. Vogel, and A. Sankarasubramanian (2000), Regional calibration of a watershed model, Hydrol. Sci. J., 45(5), 689-707.

Haude, W. (1955), Zur Bestimmung der Verdunstung auf möglichst einfache Weise, Mitt. Dtsch. Wetterdienst, 11, 1-24.

Heuvelmans, G., B. Muys, and J. Feyen (2006), Regionalisation of the parameters of a hydrological model: Comparison of linear regression models with artificial neural nets, J. Hydrol., 319, 245-265.

Horn, B. K. P. (1981), Hill shading and the reflectance map, Proc. IEEE, 69(1), 14-47.

Hundecha, Y. (2005), Regionalization of parameters of a conceptual rainfall-runoff model, Ph.D. thesis, Univ. Stuttgart, Stuttgart, Germany.

Hundecha, Y., and A. Bárdossy (2004), Modeling of the effect of land use changes on the runoff generation of a river basin through parameter regionalization of a watershed model, J. Hydrol., 292, 281-295.

Journel, A. G., and G. H. Huijbregts (1978), Mining Geostatistics, 600 pp., Academic, San Diego, Calif.

Kirkpatrick, S., C. D. Gelatt, and M. P. Vecchi (1983), Optimization by simulated annealing, Science, 220, 671-680.

Lindström, G., B. Johansson, M. Persson, M. Gardelin, and S. Bergström (1997), Development and test of the distributed HBV-96 hydrological model, J. Hydrol., 201, 272-288.

McIntyre, N., H. Lee, H. Wheater, A. Young, and T. Wagener (2005), Ensemble predictions of runoff in ungauged catchments, Water Resour. Res., 41, W12434, doi:10.1029/2005WR004289.

Merz, B., and G. Blöschl (2004), Regionalisation of watershed model parameters, J. Hydrol., 287, 95-123.

Nash, J. E., and J. V. Sutcliffe (1970), River flow forecasting through conceptual models. part I. A discussion of principles, J. Hydrol., 10, $280-290$.

Ouarda, T. B. M. J., C. Girard, G. S. Cavadias, and B. Bobée (2001), Regional flood frequency estimation with canonical correlation analysis, J. Hydrol., 254, 157-173.

Post, D. A., and A. J. Jakeman (1999), Predicting the daily streamflow of ungauged watersheds in S. E. Australia by regionalizing the parameters of a lumped conceptual rainfall-runoff model, Ecol. Modell., 123, 91104.

Seibert, J. (1999), Regionalization of parameters for a conceptual rainfallrunoff model, Agric. For. Meteorol., 98-99, 279-293.

Young, A. R. (2006), Stream flow simulation within UK ungauged watersheds using a daily rainfall-runoff model, J. Hydrol., 320, 155-172.

A. Bárdossy, Institute of Hydraulic Engineering, Universität Stuttgart, Pfaffenwaldring 61, D-70569 Stuttgart, Germany.

Y. Hundecha and T. B. M. J. Ouarda, INRS-ETE, University of Quebec, 490 de la Couronne, Quebec, QC, Canada G1K 9A9. (yeshewatesfa. hundecha@rub.de) 